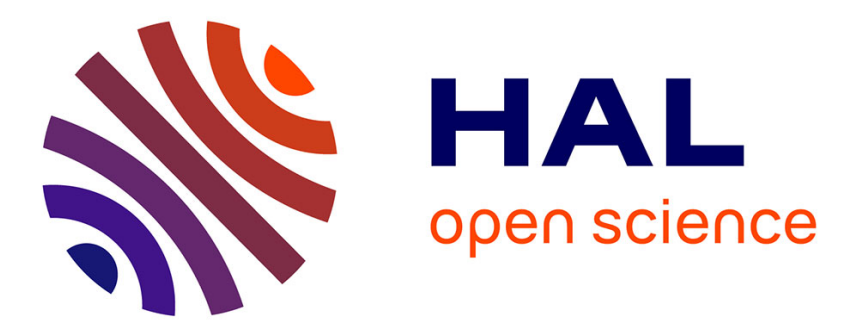

\title{
On the origin of the cracks in the dome of the Pantheon in Rome
}

\author{
Filippo Masi, Ioannis Stefanou, Paolo Vannucci
}

\section{To cite this version:}

Filippo Masi, Ioannis Stefanou, Paolo Vannucci. On the origin of the cracks in the dome of the Pantheon in Rome. Engineering Failure Analysis, 2018, 92, pp.587-596. 10.1016/j.engfailanal.2018.06.013 . hal-01719997v3

\section{HAL Id: hal-01719997 \\ https://hal.science/hal-01719997v3}

Submitted on 19 Jun 2018

HAL is a multi-disciplinary open access archive for the deposit and dissemination of scientific research documents, whether they are published or not. The documents may come from teaching and research institutions in France or abroad, or from public or private research centers.
L'archive ouverte pluridisciplinaire HAL, est destinée au dépôt et à la diffusion de documents scientifiques de niveau recherche, publiés ou non, émanant des établissements d'enseignement et de recherche français ou étrangers, des laboratoires publics ou privés. 


\title{
On the origin of the cracks in the dome of the Pantheon in Rome
}

\author{
F. Masi ${ }^{1}$, I. Stefanou ${ }^{2}$, and P. Vannucci ${ }^{* 3}$ \\ ${ }^{1}$ Laboratoire Navier - UMR8205, CNRS, ENPC \& IFSTTAR. \\ Université Paris-Est, Marne La Vallée (F) \& \\ INGEROP SA, Rueil-Malmaison (F) \\ ${ }^{2}$ Laboratoire Navier - UMR8205, CNRS, ENPC \& IFSTTAR. \\ Université Paris-Est, Marne La Vallée (F) \\ ${ }^{3}$ LMV, Laboratoire de Mathématiques de Versailles - UMR8100 CNRS \& UVSQ. \\ University Paris-Saclay, Versailles (F)
}

\begin{abstract}
In this paper we aim at giving a contribution to a problem that has been the subject of previous studies since some decades: the reason and period of formation of the meridional cracks that affect the dome of the Pantheon of Rome. This problem is investigated using a detailed three-dimensional finite-element simulation in which material nonlinearities, as well as a plausible sequence of the construction stages, are modeled. In particular, we show that concrete shrinkage, together with gravity may have been the main mechanical causes of the cracks in the early phases of the building's life. Unlike previous studies on the matter, that have largely inspired our research and where simplified 2D finite element models of the Pantheon were used, we make use of a detailed 3D model of the Pantheon's structure, that takes into account for both the particular geometry of the building, and namely the presence in the dome of a coffering and of caveas, and of the differences in the materials. The nonlinear numerical simulations, in addition, aim at reproducing, through different steps, the (probable) true constructing sequence of the dome, in order to obtain numerical results as much as possible close to reality. The results of our simulations show a rather surprising correspondence with the actual state of the dome: in fact, the overall pattern of the cracks so found is in a very good agreement with the real one, for both the number of the cracks and their extent, which shows that concrete shrinkage may have been the true reason for the presence of the meridional cracks. We have also investigated the role of the stepped rings that exist in the outer part of the dome; we show in this case that some previous studies are not necessarily contradictory, but rather complementary.
\end{abstract}

Key words: monumental structures; Pantheon in Rome; Roman concrete; cracks.

${ }^{*}$ Corresponding author: Paolo VANnUCCI. LMV, 45 Avenue des Etats-Unis. 78035 Versailles, France E-mail: paolo.vannucci@uvsq.fr 


\section{Introduction}

\subsection{The object of the study}

The Pantheon is one of the most admired and studied monuments ever ${ }^{1}$. The building that has come to us is actually the fourth Pantheon, built upon the rests of previous temples of classical rectangular form, by the Emperor Hadrian, since A.D. 118 to about 128, or later, perhaps until 140, under Emperor Antoninus Pius.

The Pantheon is probably the joint work of Hadrian and of the Nabatean great architect Apollodorus of Damascus, at least until 121, when seemingly he was first exiled by Hadrian and then executed in 125, according to Dione Cassius. Apollodorus was the architect of many great constructions during the reign of the Emperor Trajan, namely of the great bridge over the Danube, of the Trajan's Forum and Markets, of the artificial harbor of Porto and so on.

The main body of the Pantheon, the so-called Rotonda recalls, probably intentionally, the celebrated discovery of Archimedes of the volume of a sphere inscribed in a cylinder[Boyer, 1968]. In fact, see Figure 1, the Rotonda is composed by a cylinder whose inscribed sphere is coincident, for its upper part, with the dome, while its bottom touches the ground. The touch of Archimedes is present also with regard to another aspect: the coffering that is sculpted in the intrados of the dome is subdivided into 28 parts, and it was Archimedes that studied the related problem of partitioning a circle into 7 parts. The coffering, besides its aesthetic role, serves also to reduce the dome's weight.

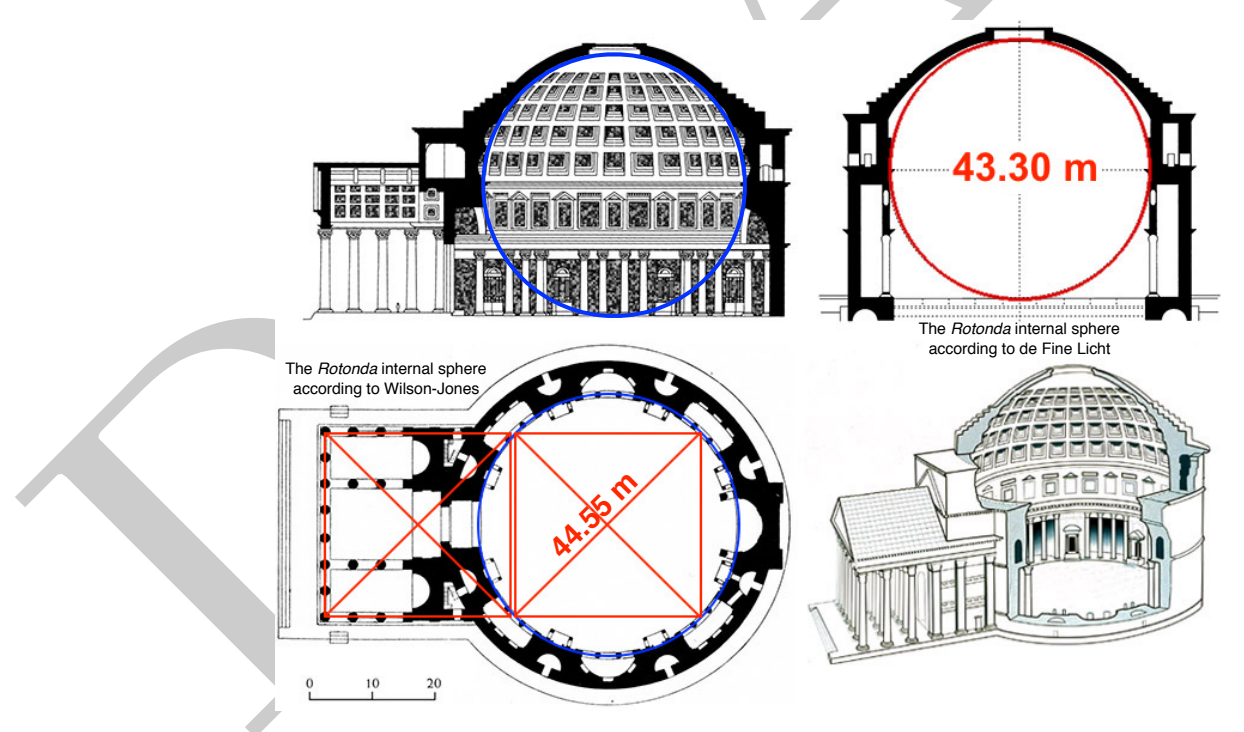

Figure 1: Scheme and dimensions of the Pantheon (from [Pulvirenti, 2014]).

With a diameter of $43.30 \mathrm{~m}$, according to the measurements of de Fine Licht [K. de Fine Licht, 1968, Mark, 1990], or 150 Roman feet, i.e., $44.55 \mathrm{~m}$, according to Wilson-Jones

1 The Pantheon has, in fact, inspired number of architects during the centuries, especially during the Neo-Classical period, e.g. P. Bianchi in the church San Francesco di Paola in Naples (1816-46), F. Bonsignore in the church Gran Madre di Dio in Turin (1818-31) or T. Jefferson in The Rotunda of the University of Virginia (1822-26). 


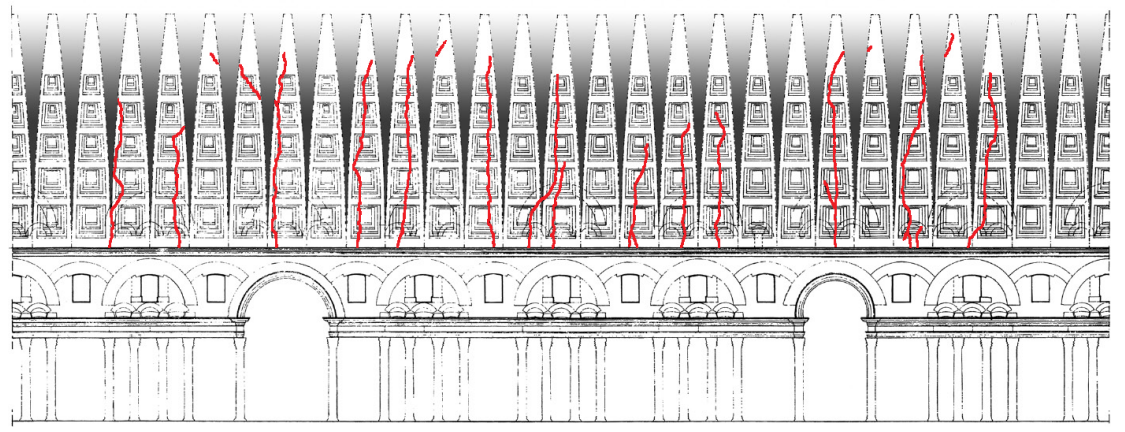

Figure 2: Meridional cracks in the Rotonda's dome (after [Terenzio, 1934]).

[Wilson-Jones, 2000, Como, 2013], the Pantheon's dome is, still today, the largest dome made of unreinforced concrete in the world ${ }^{2}$. This constructive technique, so characteristic of the Roman Empire period, was mastered by Apollodorus, who had already used it in different other buildings, e.g. the vault of the Great Hall in the Trajan's markets in Rome, see [Perucchio and Brune, 2008] [Perucchio and Brune, 2009].

While the intrados is sculpted by a coffering, the external lowest part of the dome is formed by stepped rings, see Figure 1, whose function has been the object of different investigations, related also to the object of this study.

This concerns the presence and origin of cracks in the dome. Such cracks have an almost meridional direction and stop at a latitude of approximately $57^{\circ}$, where the hoop stress begins to be compressive.

The distribution of these meridional cracks, as shown in Figure 2, was detailed in 1934 by A. Terenzio, the Superintendent of the Monuments of Latium, who had carried on a series of inspections on the dome of the Rotonda after the fall of some fragments [Terenzio, 1934]. Terenzio inferred that the cracks appeared rather soon after the construction, by noticing that some bricks used for ancient cracks repairs were marked by the same stamps with those used for the original parts of the building.

\subsection{Previous studies on the Pantheon's dome}

In an early application of Finite Element Analysis (FEA) to Roman structures, Mark and Hutchinson [Mark and Hutchinson, 1986, Mark, 1990] used a simplified two-dimensional model of the Rotonda, exploiting the axial symmetry of the structure. According to this study, and contrary to what commonly thought, the step-rings do not serve to reduce to an admissible value the hoop tension in the lowest part of the dome, due to the presence of the meridional cracks.

Mark and Hutchinson proposed different conjectures to explain the presence of the cracks: foundation settlements, shrinkage of concrete in the early phases, differential temperature

\footnotetext{
2 Actually, the Pantheon's dome is larger than the dome of Saint Peter in Vatican, diameter of which is $42 \mathrm{~m}$, and also of the octogonal dome of F. Brunelleschi, in Santa Maria del Fiore at Florence, with base circumscribed by a circle of $41.57 \mathrm{~m}$ diameter. In addition, unlike Pantheon, these two famous domes, like many others, are made of bricks, not concrete.
} 
on the dome. As far it concerns the presence of the step-rings, they gave two possible reasons. The first one is related to the construction technique: it is easier to build the lower part of the dome using the step-rings than a smooth extrados, too steep in this zone. The second, is structural: according to them, Romans probably expected, based on experience, the dome to be cracked since the beginning, which changes dramatically its static regime as the hoop stress cannot be transmitted anymore through the dome. Therefore, the whole behavior of the Rotonda is more similar to that of an array of wedgeshaped $\operatorname{arches}^{3}$, and in this case, the use of the step-rings is substantial: their action is like that of an overload over the haunch of an arch. Using an iterative procedure, they showed that if tensile stresses are not permitted, cracks extend up to $54^{\circ}$, value which is in agreement with the observed cracks of the dome. Finally, the basic idea of Mark and Hutchinson is that Romans knew that meridional cracks in unreinforced concrete domes were inevitable and present since the first period after the construction, which is proved by the construction of the step-rings.

Recently, the conclusions of Mark and Hutchinson have been criticized by Brune in his $\mathrm{PhD}$ thesis [Brune, 2010]. Brune has used a FEA of the Rotonda similar to that of Mark and Hutchinson, i.e., using a two-dimensional model with imposed axi-symmetry. The conclusion drawn is exactly the opposite, and namely that the step-rings improve the hoop resistance of the dome leading to a reduction of the hoop stress with respect to the case without step-rings. As far it concerns the cracks, without firmly propounding a specific cause, Brune seems to indicate foundation settlements the most likely reason for the cracks and rises some doubts on the cracks origin time by arguing that the bricks used for repairs have been actually used in the exterior of the Rotonda. According to Brune, this shows that the dome cracks documented by Terenzio cannot be dated back with sufficient confidence to a period close to the construction of the monument. They could have appeared at that time, for instance in the form of micro-cracks which propagated further the cracks opening, over a long period, probably due to ground settlements and/or earthquakes.

\subsection{Motivation of the present study}

The analysis of Mark and Hutchinson, based on a 2D model, makes use of an iterative procedure to introduce the formation and propagation of the meridional cracks as consequence of a too high tensile hoop stress. However, in doing so, the axial symmetry is no more a valid assumption and, though they arrive to a rather correct value of the cracks extension, it is questionable wether or not their $2 \mathrm{D}$ model is really representative of the $3 \mathrm{D}$ problem. Actually, the conclusion of Brune, still based on a 2D model, is opposite to that of Mark and Hutchinson.

Morer and Goñi have proposed in 2008 a study based on a 3D detailed Finite Element (FE) model of the Rotonda, but without taking into account the coffering [Morer and Goñi, 2008]. Their study seems not to be focused on the origin of the cracks, because such cracks are already part of their model and are used uniquely to assess the subsequent

\footnotetext{
${ }^{3}$ This situation is typical also of many masonry domes, see e.g. [Blasi and Foraboschi, 1994, Foraboschi, 2016].
} 
stress distribution. Therefore, to the authors knowledge, an accurate 3D study oriented to determine the possible origin of the meridional cracks is still lacking.

The study we present is, in fact, a contribution to this technical and historical problem and it tries to give a possible explanation of the cracks origin through the simulation of the building phases. Namely, we investigate, including the early transient phase of concrete setting, whether or not concrete shrinkage could have been able to produce a crack pattern of the type observed by Terenzio. The study relies on numerical simulations with a detailed 3D FE model of the Rotonda, making use of a nonlinear constitutive law.

The results reveal a crack pattern which is in good accordance with the observed one. This allows us to presume that concrete shrinkage and gravity are likely to be the two main mechanical causes of the cracks and that these last may really be arisen in the early phases of the building's life. Of course, as for any inverse problem, it is difficult to exclude other factors and causes, such as ground settlements, so in the end our analysis clearly shows that the conjugate effect of concrete shrinkage and gravity is a sufficient condition for explaining the presence and the formation period of the observed meridional cracks.

Such a result is to be ascribed to the technology used by Romans for the construction of the Pantheon's dome: a structure in unreinforced concrete is, one one hand, submitted to the phenomenon of shrinkage and to gravity, on the other hand, like masonry or stone structures, unreinforced concrete can withstand only low tension stresses. The combined final effect is the appearance of cracks in the dome.

Finally we address the previously risen issue on the effect of the presence of the step-rings in the Rotonda's state of stress and we compare the results with those given in [Mark and Hutchinson, 1986] and [Brune, 2010].

\section{Modeling the material behavior}

Pantheon is made by different materials and we have considered five different zones, corresponding to those indicated in Figure 3: foundation, brick-faced concrete of the cylindrical wall, lower, intermediate and upper zone of the dome. The columns are made of granite. Concerning the dome, it is composed of different aggregates, from the heaviest one in the lower part, with thickness $\sim 5.9 \mathrm{~m}$, to the lightest one in the upper part of the dome, where the thickness decreases to $\sim 1.5 \mathrm{~m}$.

The materials are assumed homogeneous and linearly elastic in compression. It is commonly considered that in monumental structures compression stresses are very low, usually an order of magnitude below the compressive strength of the material, cf. [Heyman, 1995, Stefanou et al., 2015], so that there is no possibility of crushing. The consistency of this modelling assumption is hence checked by monitoring that the compressive stresses do not exceed the compressive strength, assumed to be, for concrete, equal to $\sim 5 \mathrm{MPa}$, according to the experimental results by [Samuelli-Ferretti, 1996] and [Giavarini et al., 2006] and the models proposed in [Brune, 2010] and [Ivancic et al., 2014], and $\sim 123 \mathrm{MPa}$ for granite, see [Buyukozturk, 1993]. 


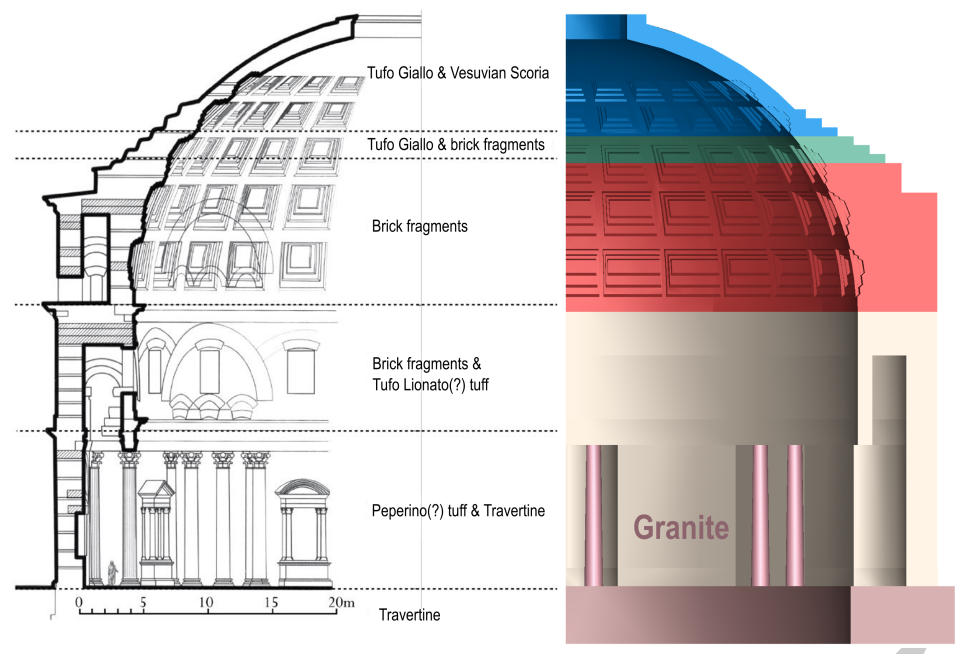

Concrete 5

Concrete 4

Concrete 3

Concrete 2

Concrete 1

Figure 3: Materials composing the Rotonda as in [Lancaster, 2005] (left) and in Table 1.

Under tension, a linear elastic behavior is assumed until the maximum principal stress reaches the tensile strength, $f_{t}$. A subsequent tensile softening is considered in terms of the nonlinear brittle cracking model proposed in [Hillerborg et al., 1976, ABAQUS, 2016]. According to this law, when the maximum principal stress reaches $f_{t}$, a fictitious crack is formed in the plane orthogonal to the direction of the principal tensile stress. We assume, for the sake of simplicity, that the orientation of the planar Mode I crack remains constant in the three-dimensional space. Once the peak tensile stress is reached, a linear softening branch is followed based on the fracture energy $G_{f}$. This allows to minimize mesh dependency due to the softening behavior and to dissipate adequately the energy in the numerical simulations [ABAQUS, 2016].

For what concerns the choice of the mechanical characteristics of the materials, the densities have been fixed upon the indications given in [Mark and Hutchinson, 1986], while the other properties have been derived upon the identification of a rationale link to the densities so that, starting from few known data, the other ones can be assessed. Indeed, according to historians and researchers in mechanics of ancient monuments, the physical properties of concretes and mortars of the past have different characteristics with respect to modern concrete. In particular, as already said, the Pantheon's dome has been realized by the Roman concrete, based on the use of the pozzolana, a pumice stone of volcanic origin, and of different aggregates, from ordinary gravel in the lower part to pumice aggregates in the upper part, so as to obtain a material whose density decreases from the bottom to the top of the dome.

Unfortunately, the data that can be found in the literature on Roman concrete are not systematic nor complete. However, experimental tests have shown that the tensile behavior of Roman concrete follows that of mortar (see [Samuelli-Ferretti, 1997, Giavarini et al., 2006, Jackson et al., 2009]), due to a rather low contrast of the tensile strength between the Roman concrete's aggregates and the mortar itself [Jackson et al., 2009]. This gives a material which is less heterogeneous than modern concrete and which behaves more as a mortar, at least in the traction regime. Consequently, it is possible to model Roman concrete as an equivalent mortar, in the absence of more precise experimentally derived mechanical properties. 
For all the concretes, we have assumed a Poisson's ratio $\nu=0.2$, as proposed in [Como, 2013]). The Young's moduli for concrete aggregates of the dome and the cylindrical part are derived from [Brune, 2010] and [Como, 2013], respectively. Based on modern technical recommendations for lightweight concrete [Sanpaolesi and Formichi, 2009], relationships between the Young's modulus, tensile strength and density have been extrapolated. Concerning the fracture energy, we have used the linear relationship in [Dehn, 2004]. For more details the reader is addressed to [Masi, 2017] and [Masi et al., 2018].

Regarding the concrete composing the dome, we have considered the material properties in [Brune, 2010], where some typical values of different material parameters, and namely the Young's modulus, $E, f_{t}$, and $G_{f}$, as well as a bilinear approximation of the experimental softening curve, are reported for a reproduction of ancient Roman mortar as a function of the curing duration. Since we are dealing with the simulation of the shrinkage of concrete, the interesting values for the present analysis are those referring to 28 days.

Table 1 shows the material parameters for the different zones of the model.

Table 1: Materials data

\begin{tabular}{llccccc}
\hline Material & Part & $\begin{array}{c}\rho \\
{\left[\mathrm{kg} / \mathrm{m}^{3}\right]}\end{array}$ & $\begin{array}{c}E \\
{[\mathrm{GPa}]}\end{array}$ & $\nu$ & $\begin{array}{c}G_{f} \\
{\left[\mathrm{~J} / \mathrm{m}^{2}\right]}\end{array}$ & $\begin{array}{c}f_{t} \\
{[\mathrm{MPa}]}\end{array}$ \\
\hline Granite & Columns & 2500 & 55.3 & 0.16 & 17.5 & 3.50 \\
Concrete 1 & Foundations & 2000 & 13.5 & 0.20 & 62.1 & 0.68 \\
Concrete 2 & Cylindrical wall & 1750 & 7.0 & 0.20 & 59.4 & 0.63 \\
Concrete 3 & Lower dome & 1600 & 1.0 & 0.20 & 5.0 & 0.08 \\
Concrete 4 & Intermediate dome & 1500 & 1.0 & 0.20 & 5.0 & 0.08 \\
Concrete 5 & Upper dome & 1350 & 1.0 & 0.20 & 5.0 & 0.08 \\
\hline
\end{tabular}

\section{$3 \quad$ Numerical simulations}

The target of this study is the assessment of the role of initial shrinkage in the formation of the meridional cracks that spread across the dome. Concrete hardening is a complex thermo-hydro-mechanical process characterized by exothermic chemical reactions and internal drying that cause also volume change, especially in the early stages of curing, known as shrinkage. In the present analysis, only the mechanical effects of the process of shrinkage is considered by modeling it as an imposed volume change, $\varepsilon_{v}$, produced by an equivalent change of temperature $\Delta T<0$ :

$$
\varepsilon_{v}=\alpha \Delta T
$$

where $\alpha$ is the thermal expansion coefficient. In fact, the overall effects of concrete shrinkage and temperature change are the same: a change of volume. The numerical simulations performed simulating the shrinkage of the concrete by a decrement of the temperature are hence correct to represent the phenomenon, provided that the temperature decrease used in the numerical simulations is quantitatively correct.

Shrinkage depends on the amount of water used to mix the aggregates, curing time and ambient relative humidity, among other parameters, and for modern concrete amounts 
to a volume change $\varepsilon_{v}=0.15 \div 0.30 \times 10^{-3}$. For the problem at hand, a parametric analysis at varying of the ratio $\varepsilon_{v} / \alpha$, thus of $\Delta T$, seems to be a good choice to overcome the uncertainties of selecting, in the case of Roman concrete, realistic values for both the volumetric straining and the thermal expansion coefficient.

The procedure used for simulating the effects of initial shrinkage in concrete, occurred during the construction of the dome, requires a proper characterization of the casting process. To this purpose, the following hypotheses are made:

a. The dome was cast by pouring concrete over a wooden formwork [Como and Grimaldi, 2004], assumed to be self-supporting;

$b$. The frames are left in position to allow the structure to harden; we assume that, once the concrete has set, the formworks are left in place to let the concrete reach a sufficient strength. Shrinkage happens during this phase.

c. The formwork is finally removed, and the dome can freely deform under the action of its own weight.

The simulation is accordingly split in three different steps:

1. First, we apply the gravity to the structure, which is supported by formworks. The application of the load is done through an implicit static analysis.

2. The results obtained are then used as the initial state of a subsequent nonlinear explicit analysis in which the volume change due to shrinkage is simulated by an incrementally applied thermal load, $\Delta T$. The load is applied slowly in order to minimize dynamic effects.

The presence of the self-supporting formwork is modeled by imposing a zero vertical displacement at the inner face of the dome.

3. A second explicit analysis finally models the progressive decentering of frames by removing the boundary condition corresponding to the self-supporting formwork progressively to ensure that no inertial effects take place, meaning that the kinetic energy of the system is neglectable $(<5 \%)$ with respect to strain energy, [ABAQUS,
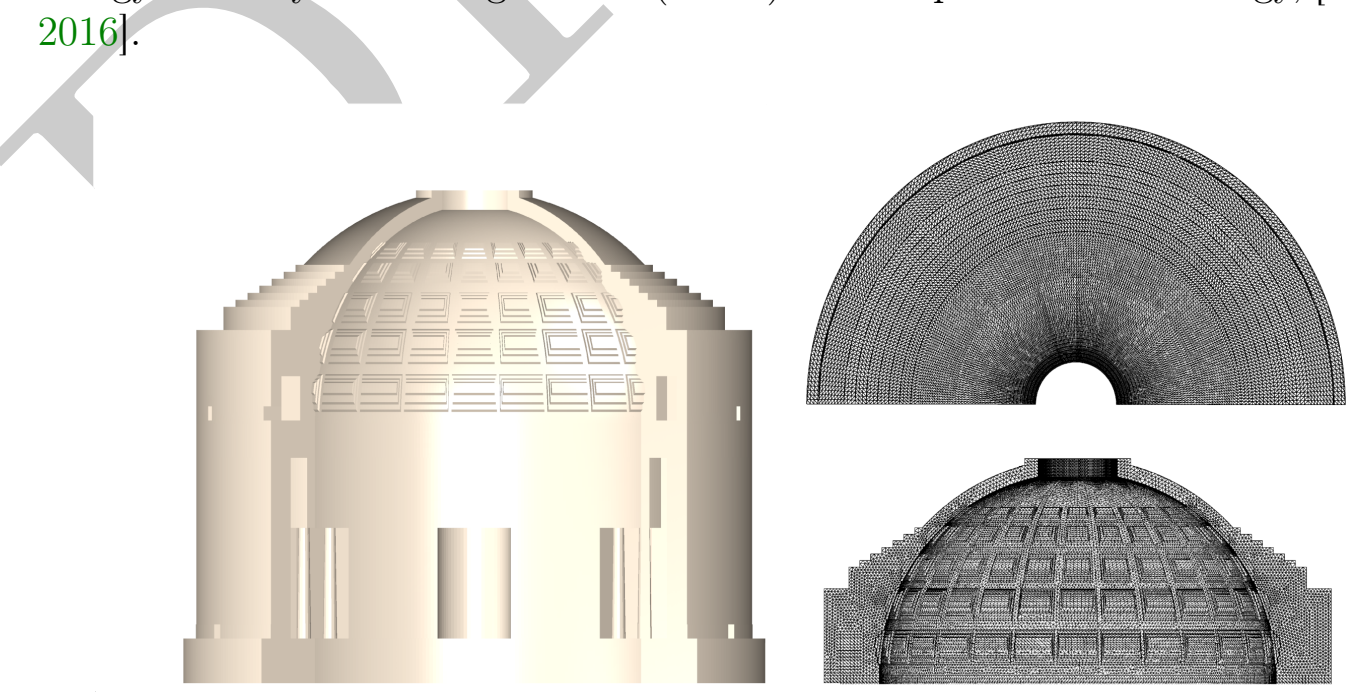

Figure 4: Geometrical model of the Rotonda and a detail of the dense FE Mesh. 
The nonlinear simulations are done assuming a mass-proportional damping for the explicit analyses in order to reach equilibrium rapidly and dissipate undesirable inertial effects (quasi-static condition). We have used a FEM composed of 3.7 millions of deegres of freedom (DOF), made of four-nodes thermally coupled tetrahedral elements, see Figure 4. This choice has been done after a mesh convergence analysis, as explained in [Masi et al., 2018].

We have simulated the shrinkage of the dome for different volumetric straining to thermal expansion coefficient ratios, starting from a $\left(\varepsilon_{v} / \alpha\right)_{1}=3.4 \mathrm{~K}$ till $\left(\varepsilon_{v} / \alpha\right)_{5}=4.55 \mathrm{~K}$, which corresponds to the maximum value of $\varepsilon_{v} / \alpha$ if a stable configuration has to be found for the dome, at the end of the simulations, through equally-spaced increments. For each ratio, we have monitored the average and maximum latitude reached by the meridional cracks above the springing, $\theta_{\text {mean }}$ and $\theta_{\text {max }}$ respectively, and the azimuthal frequency, i.e.,, the reciprocal of the average azimuthal angle between two consecutive cracks, $f_{\varphi}=1 / \varphi_{\text {mean }}$ (see Fig. 5). Table 2 shows the results of the calculations and Figure 6 the relative crack patterns.

Table 2: Number of cracks, average and maximum latitude and azimuthal frequency.

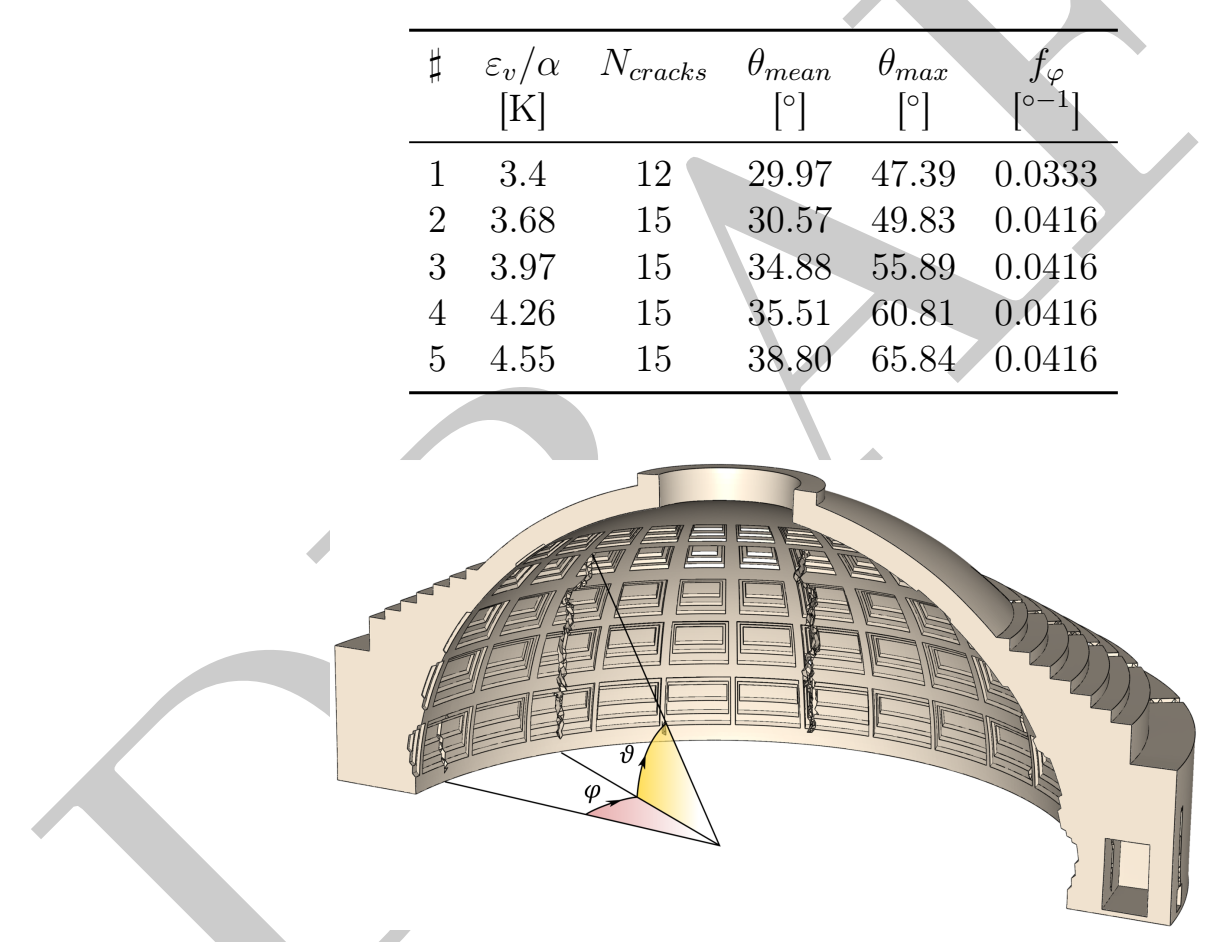

Figure 5: Schematic representation of polar and azimuthal angles.

We can clearly notice a sort of invariance of the azimuthal frequency for $\varepsilon_{v} / \alpha \geq\left(\varepsilon_{v} / \alpha\right)_{2}$ : fifteen meridional cracks spread the dome independently from the volumetric strain, thus from the amount of shrinkage. This value coincides almost perfectly with that reported by Terenzio of fourteen major cracks. This can be put into correspondence with the existence of fifteen equally-spaced caveas present at the base of the dome itself: all the major cracks stem from such caveas to propagate meridionally throughout the dome (see Fig. 7). The slight difference in the azimuthal frequency could, however, be explained if one considered the presence of the pronaos located at the entrance of the Pantheon (see Fig. 9), which, if constructed at the same time of the dome, could have prevented the formation of 


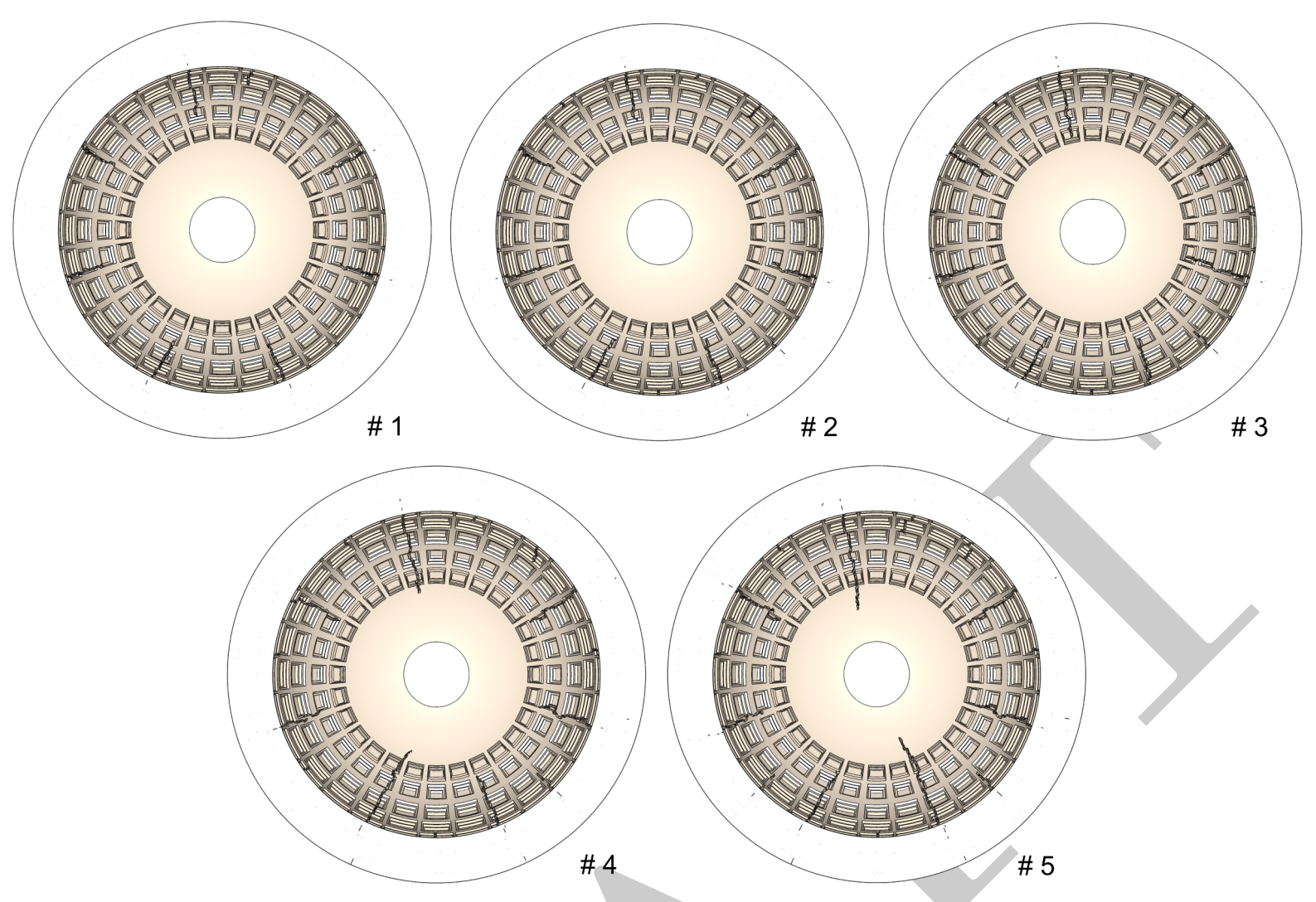

Figure 6: Crack patterns at the end of the calculations for the different volumetric straining to thermal expansion coefficient ratios, as defined in Table 2.

the fifteenth crack above the entrance door, by limiting the volumetric straining of the contiguous part of the dome. Indeed, looking at the pattern photographed by Terenzio (Fig. 2), we can notice a sort of symmetry to a plane passing from the extremities and the center of the figure itself. That is, with respect the plane of symmetry of the building. Moreover, the azimuthal distance between the first left-hand side and the last right-hand side cracks is higher with respect to all the other ones, suggesting the explanation argued above. Figure 9 shows a schematic representation of the possible crack pattern with fourteen cracks.

The subsequent decentering of the dome and gravity action plays a less relevant role with respect to shrinkage in the development of cracks, as clearly depicted in Figure 8. Indeed, the cracks with tip's latitude reaching a value higher than that where tensile hoop stresses become compressive (for a hemispherical dome of uniform thickness this theoretically occurs at a latitude $\theta \cong 52^{\circ}$, see [Flügge, 2013]), do not evidently propagate further in the (macroscopic) equilibrium configuration of the dome.

\section{The role of step-rings}

In evaluating the effect of step-rings on the state of stress of the Pantheon's dome, the opposite and controversial results given by Mark and Hutchinson [Mark and Hutchinson, 1986] and Brune [Brune, 2010], as we highlighted in Section 1.3, need explanation. To 

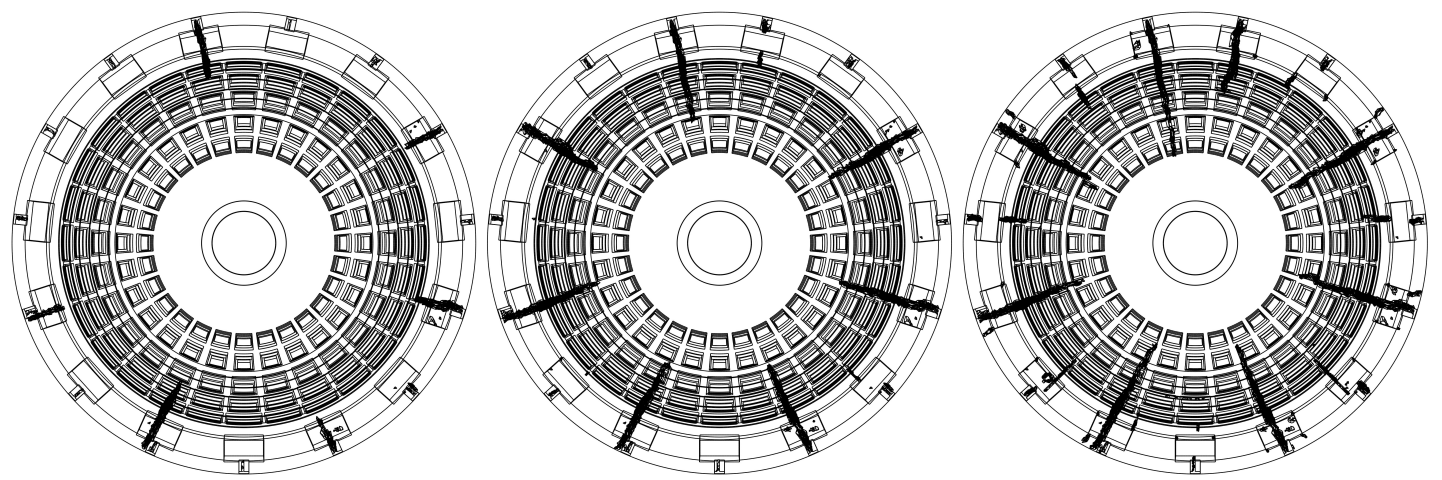

Figure 7: Progressive cracking of the dome due to an incrementally applied thermal load of $\left(\varepsilon_{v} / \alpha\right)_{5}=4.55 \mathrm{~K}$, during step 2) (plan view).

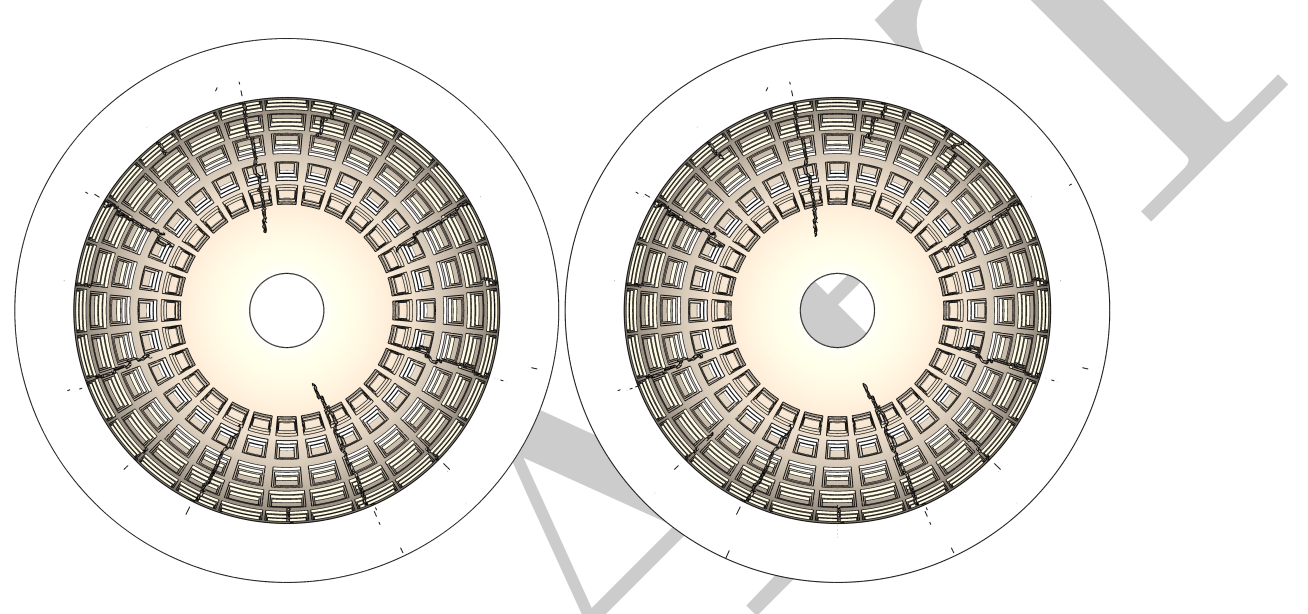

Figure 8: Final crack patterns at the end of the calculations of steps 2) (left) and 3) (right), for $\left(\varepsilon_{v} / \alpha\right)_{5}=4.55 \mathrm{~K}$.

this purpose, we investigate the static response of the Pantheon under its own weight with and without step-rings, using a 3D and a 2D axi-symmetric model.

In the light of the simulations (see Fig. 10), we observe that the presence of step-rings results in a decrease of the hoop stresses with respect to the model without step-rings; the maximum hoop stress in the former configuration is found to be $\sim 27.1 \%$ lower than the one developped in the latter.

The results we find agree with those reported in [Brune, 2010], although the percentage of decrease of the hoop stresses reported by the author is higher $\sim 58.5 \%$. The difference probably comes only from the simplified choice of the material densities made in [Brune, 2010], where the entire structure is subdivided into 3 regions: foundations and cylindrical part with $\rho=1750 \mathrm{~kg} / \mathrm{m}^{3}$, lowermost and uppermost parts of the dome with $\rho=1500$ $\mathrm{kg} / \mathrm{m}^{3}$ and $\rho=1350 \mathrm{~kg} / \mathrm{m}^{3}$, respectively. While, as explained in Sec. 2, we decided to follow the indications for the densities given in [Mark and Hutchinson, 1986] and the scheme represented in Figure 3 and Table 1. Moreover, from the cracked configuration of the dome, as found by modeling shrinkage, we can easily check that the dome behaves like an array of wedge-shaped arches and that the hoop stresses are even lower than those of the configuration without stepped rings. 

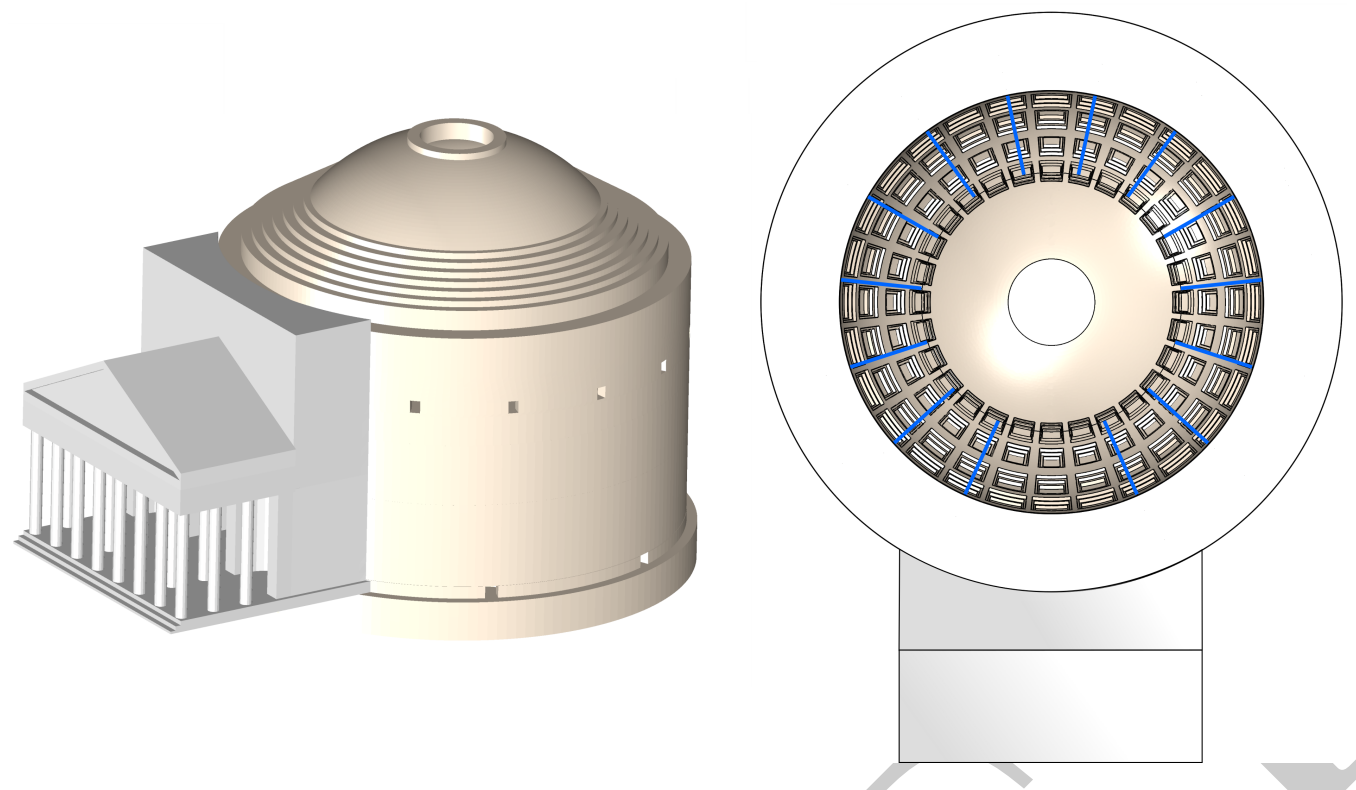

Figure 9: View of the Rotonda and pronaos, left. Possible pattern of 14 cracks (in blue), still formed from the caveas at the base of the dome, due to the presence of the pronaos.
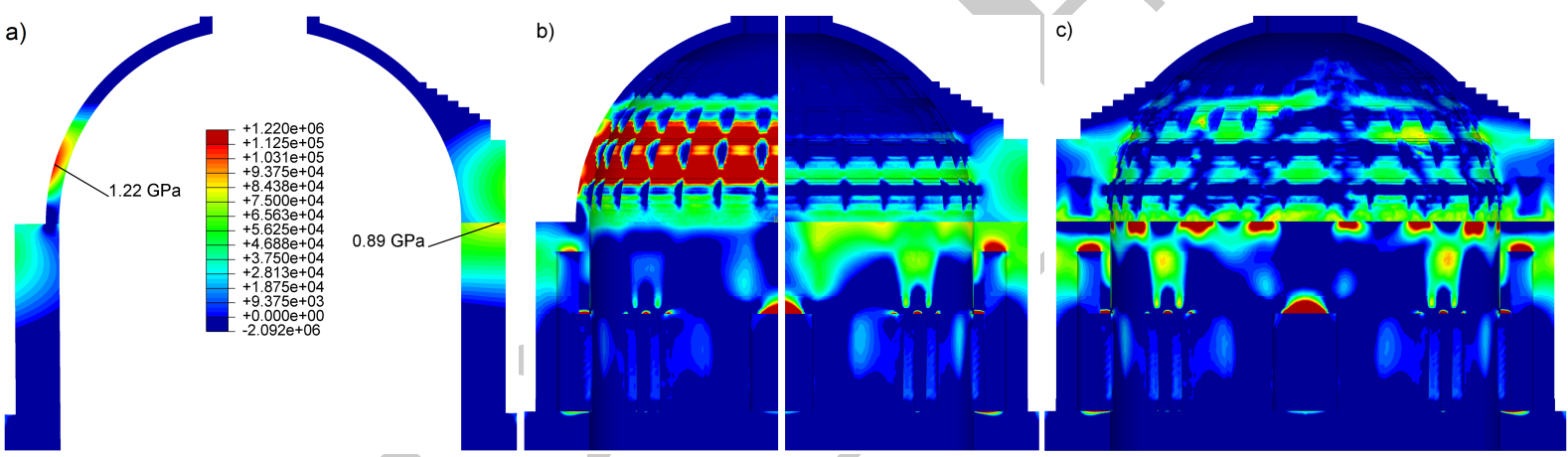

Figure 10: Hoop stresses due to self-weight with and without stepped rings: a) 2D axisymmetric, b) 3D model, and c) 3D model at the end of the shrinkage calculations, $\left(\varepsilon_{v} / \alpha\right)_{5}=4.55 \mathrm{~K}$ (cracks are not displayed).

\section{Conclusion}

The study presented in this paper concerns an investigation on $i$ ) the possible cause of the origin of the meridional cracks that are observed in the dome and $i i$ ) the effect of the presence of the step-rings in the structure's state of stress.

The investigation consists of a numerical simulation, carried on an accurate 3D FE model of the Pantheon's structure, where the distinctive geometrical details of the monument, such as the internal dome coffering, the external stepped rings and the caveas in the dome itself, are considered. Furthermore, the different materials used to built the Rotonda, whose characteristics have been derived using published data, are modeled and their behavior is described in terms of a nonlinear constitutive law accounting for tensile softening and damage. Finally, a plausible sequence of the dome's construction is assumed to model the initial stages of the life of the structure. 
This research has been motivated by some previous studies, namely [Mark and Hutchinson, 1986, Brune, 2010] and should be intended as a continuation of them. We point out, in fact, that for its characteristics our study is a step forward with respect to the cited studies: the use of an accurate 3D model, of a nonlinear constitutive law and the simulation of a plausible sequence of construction phases are in fact new with respect to the previous cited studies.

The study presented in this paper shows that the meridional cracks may have been produced in the early stage of the dome's life by the action of concrete shrinkage and gravity. In fact, we retrieve the same cracking pattern of the one observed in situ: both the cracks spatial distribution (fifteen in number) and their extent agree remarkably well with the observed cracks [K. de Fine Licht, 1968]. Of course, it is not possible to affirm with absolute certainty that concrete shrinkage and gravity are the only responsible for the presence of the meridional cracks, but we can reasonably confirm, with our study, the conjecture suggested by the cited authors: these two causes are sufficient to produce the observed effect and, finally, the conjugate effect of concrete shrinkage and of gravity is likely to be the true reason for the appearence of the meridional cracks in the Pantheon's dome since its first period of life.

We have also investigated the role of the stepped rings on the exterior lower part of the dome. In fact, also in this case the opinions of the researchers diverge. Our study shows that Mark's and Hutchinson's conclusions and Brunes's are complementary rather than contradictory. Indeed, we show that the structural role of the stepped rings is twofold. On one hand, as stated by Brune, they reduce the hoop tensile stresses in the dome and, on the other hand, as stated by Mark and Hutchinson, they provide additional loading to the cantilever-like mechanism formed by the existing meridional cracks. On the whole, they have a positive impact on the structure, improving its stability.

\section{References}

ABAQUS. Abaqus analysis user's guide. Technical Report Abaqus 6.14 Documentation, Simulia Corp., 2016.

C. Blasi and P. Foraboschi. Analytical approach to collapse mechanisms of circular masonry arch. Journal of Structural Engineering, 120:2288-2309, 1994.

C. B. Boyer. A history of mathematics. J. Wiley \& Sons, New York, 1968.

Ph. F. Brune. The Mechanics of Imperial Roman Concrete and the Structural Design of Vaulted Monuments. PhD thesis, Department of Mechanical Engineering - University of Rochester, Rochester, NY, 2010.

O. Buyukozturk. Interface fracture and crack propagation in concrete composites. In C. Huet, editor, Micromechanics of concrete and cementitious composites, pages 203212, Lausanne, Switzerland, 1993. Presses Polytechniques et Universitaires Romandes.

M. Como. Statics of historic masonry constructions. Springer Verlag, Berlin, Germany, 2013. 
M. Como and A. Grimaldi. Large structures behaviour: the past and the future. In Novel Approaches in Civil Engineering, pages 47-79. Springer, 2004.

F. Dehn. Fracture mechanical behaviour of lightweight aggregate concrete. In Fracture mechanics of concrete structures. Proceedings of International conference on fracture mechanics of concrete and concrete structures., Vail, Colorado, 2004.

W. Flügge. Stresses in shells. Springer Science \& Business Media, 2013.

P. Foraboschi. The central role played by structural design in enabling the construction of buildings that advanced and revolutionized architecture. Construction and Building Materials, 114:956-976, 2016.

C. Giavarini, A. Samuelli Ferretti, and M. L. Santarelli. Mechanical behaviour and properties. In S. K. KOURKOULIS, editor, Fracture and Failure of Natural Building Stones: Applications in the Restoration of Ancient Monuments, pages 107-120. Springer Netherlands, Dordrecht, 2006.

J. Heyman. The stone skeleton. Cambridge University Press, Cambridge, UK, 1995.

A. Hillerborg, M. Modéer, and P. E. Petersson. Analysis of crack formation and crack growth in concrete by means of fracture mechanics and finite elements. Cement and Concrete Resistance, 6:773-782, 1976.

S. Ivancic, P. Brune, and R. Perucchio. A Concrete Damage Plasticity Model for Ancient Roman Pozzolanic Concrete. In Proc. of the 9th International Masonry Conference, Guimarães, Portugal, 2014.

M. D. Jackson, J. M. Logan, B. E. Scheetz, D. M. Deocampo, C. G. Cawood, F. Marra, M. Vitti, and L. Ungaro. Assessment of material characteristics of ancient concretes, Grande Aula, Markets of Trajan, Rome. Journal of Archaeological Science, 36:24812492, 2009.

K. de Fine Licht. The Rotunda in Rome: a study of Hadrian's Pantheon. Jutland Archeological Society, Copenhagen, Denmark, 1968.

L. C. Lancaster. Concrete Vaulted Construction in Imperial Rome. Cambridge University Press, New York, NY, 2005.

R. Mark. Light, wind and structure. The MIT Press, Cambridge, Massachussets, 1990.

R. Mark and P. Hutchinson. On the Structure of the Roman Pantheon. The Art Bulletin, 68:24-34, 1986.

F. Masi. Blast actions from high explosives. Studies on their simulation and effects. Master Thesis - Department of Mechanical Engineering - University of Florence, 2017. doi: 10.17605/osf.io/ekus8.

F. Masi, I. Stefanou, and P. Vannucci. A study on the effects of an explosion in the Pantheon of Rome. Engineering Structures, 164:359-273, 2018.

P. Morer and R. Goñi. A benchmarking study of the analysis of non-reinforced structures applied to the structural behavior of domes. In Structural Analysis of Historic Construction: Preserving Safety and Significance, Two Volume Set: Proceedings of the 
VI International Conference on Structural Analysis of Historic Construction, SAHC08, 2-4 July 2008, Bath, United Kingdom, pages 705-713. CRC Press, 2008.

R. Perucchio and P. Brune. Concrete vaulting in Imperial Rome: A structural analysis of the Great Hall of Trajan's Markets. In J. F. Abel and J. R. Cooke, editors, Proc. of the 6th International conference on Computation of Shell and Spatial Structures, Cornell University, Ithaca, NY, 2008.

R. Perucchio and P. Brune. The Evolution of Structural Design of Monumental Vaulting in Opus Caementicium in Imperial Rome. In Proceedings of the Third International Congress on Construction History, Cottbus, Germany, May 2009.

E. Pulvirenti. Didatticarte, 2014. URL http: //www . didatticarte. it/Blog/?p=2169.

A. Samuelli-Ferretti. Materiali da costruzione e tecnologie costruttive del patrimonio archeologico e monumentale romano con particolare riferimento al tipo laziale ed all'opus latericium. Technical report, Dipartimento di Ingegneria Strutturale e Geotecnica - University of Rome "La Sapienza", Rome, Italy, 1996.

A. Samuelli-Ferretti. Proposte per lo studio tecnico-sperimentale della statica dei monumenti in opus caementicum. Journal of Archeological Science, 36:2481-2492, 1997.

L. Sanpaolesi and P. Formichi. Calcestruzzo leggero strutturale di argilla espansa. Leca, Parme, Italy, 2009.

I. Stefanou, K. Sab, and J.-V. Heck. Three dimensional homogenization of masonry structures with building blocks of finite strength: A closed form strength domain. International Journal of Solids and Structures, 54:258-270, 2015.

A. Terenzio. La restauration du Panthéon de Rome. In La Conservation des Monuments d'Art $\&$ d'Histoire, pages 280-285. Office International des Musées, Paris, France, 1934.

M. Wilson-Jones. Principles of Roman Architecture. Yale University Press, New Haven, Connecticut, 2000.

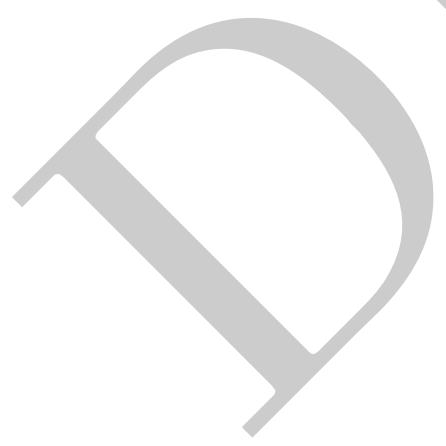

